\title{
Understanding the Sport Event Volunteer Experience: An Investigation of Role Ambiguity and Its Correlates
}

Rogalsky, K., Doherty, A., \& Paradis, K. F. (2016). Understanding the Sport Event Volunteer Experience: An Investigation of Role Ambiguity and Its Correlates. Journal of Sport Management, 30(4), 453-469. https://doi.org/10.1123/jsm.2015-0214

Link to publication record in Ulster University Research Portal

\section{Published in:}

Journal of Sport Management

Publication Status:

Published (in print/issue): 01/07/2016

DOI:

10.1123/jsm.2015-0214

\section{Document Version}

Author Accepted version

\section{General rights}

Copyright for the publications made accessible via Ulster University's Research Portal is retained by the author(s) and / or other copyright owners and it is a condition of accessing these publications that users recognise and abide by the legal requirements associated with these rights.

\section{Take down policy}

The Research Portal is Ulster University's institutional repository that provides access to Ulster's research outputs. Every effort has been made to ensure that content in the Research Portal does not infringe any person's rights, or applicable UK laws. If you discover content in the Research Portal that you believe breaches copyright or violates any law, please contact pure-support@ulster.ac.uk. 


\begin{abstract}
The present study tested a theoretical model of the correlates of role ambiguity of major sport event volunteers. The sample consisted of 328 volunteers involved with the 2012 Ontario Summer Games. Participants completed an on-line questionnaire post-Games that included measures of role ambiguity, role difficulty, training, supervision, effort, performance, role satisfaction, overall satisfaction with the Games, and future volunteer intentions. Findings provide support for a multidimensional model of role ambiguity, consisting of performance outcomes ambiguity and means-ends/scope ambiguity in this context. A final model indicated that perceived effective supervision was inversely associated with both dimensions of ambiguity, and they differentially predicted role effort, performance and role satisfaction. Role performance and role satisfaction predicted overall satisfaction with the Games experience, which was significantly asscociated with future intentions to volunteer. Implications for sport event volunteer management and suggestions for future research are discussed.
\end{abstract}

Keywords: role ambiguity, satisfaction, sport event volunteers 
Understanding the Sport Event Volunteer Experience: An Investigation of Role Ambiguity and its Correlates

There is a heavy reliance on volunteers to organize and implement all types and sizes of sport events (Cuskelly, Hoye, \& Auld, 2006). The effort and performance of those volunteers in the various roles they undertake is vital to the success of the events (Cuskelly et al., 2006), and satisfaction with those roles may have some bearing on their interest and intention to volunteer again (Doherty, 2009). Roles, a common structural element of all groups, refer to the pattern of behaviour expected of individuals (Carron \& Eys, 2012; Katz, Kahn, \& Adams, 1978). Formal roles are those imposed by the group or organization that the individual is a part of (Carron \& Eys, 2012). Sport event volunteers can be asked to take on any one or more of a variety of roles that can range from pre-event planning and organizing, to on-site competitor registration, merchandise sales, event marshalling and providing general assistance to athletes (Allen \& Shaw, 2009; Shaw, 2009). Their clear understanding of their role(s) - for example, what one is expected to do at the event's welcome centre, how to process sales or stock merchandise at a retail booth, what difference it makes if one shows up late for a shift, or not at all - may be expected to shape their contribution to the event. However, that clarity may be challenging in the fast-paced, short term and temporary sport event environment (Emery, 2003), where one may be faced with multiple and new tasks, that vary in their complexity (Cuskelly et al., 2006). Thus, consideration of volunteers' understanding of their role(s), and factors associated with that, is important for effective event volunteer management.

Indeed, role theory suggests that clarity, or the converse - role ambiguity - may be critical to effort, effective performance and satisfaction regarding one's role, and intention to continue to engage, or engage again, in that role. Role ambiguity refers to a lack of clear 
understanding about the actions required to perform one's role (Kahn, Wolfe, Quinn, Snoek, \& Rosenthal, 1964). According to Kahn et al. (1964), there may be ambiguity with regard to: (1) what one is expected to do, (2) how to perform one's role, (3) whose expectations are given priority, (4) how one's performance is evaluated, and (5) the consequences of completing or not completing one's responsibilities. The impact of role ambiguity, on the individual and the organization, has been reported in a variety of contexts, and includes decreased effort (Brown \& Peterson, 1994; Sakires, Doherty, \& Misener, 2009), decreased performance (Doherty \& Hoye, 2011; Ortqvist \& Wincent, 2006; Tubre \& Collins, 2000; Wolverton, Wolverton, \& Gmelch, 1999), and decreased satisfaction (Jackson \& Schuler, 1985; Sakires et al., 2009; Thompson, McNamara, \& Hoyle, 1997; Wolverton et al., 1999). A compromised understanding of what is expected, how one will be evaluated, whose expectations are most important when there are multiple and even conflicting demands, and so on, are likely to be accompanied by reduced effort in one's role, lesser performance, and lower satisfaction; all factors that may be expected to have consequences for organizational efficiency and effectiveness.

A few studies have examined role ambiguity in the volunteer sport setting specifically (Doherty \& Hoye, 2011; Sakires et al., 2009; Schulz \& Auld, 2006). It is contended that imprecise objectives and multiple stakeholders with potentially competing interests characterize voluntary organizations (e.g., Carver, 1997; Papadimitriou \& Taylor, 2000) and contribute to ambiguity regarding the nature and scope of volunteers' roles there (e.g., Merrell, 2000; Pearce, 1993). Although low levels of ambiguity are reported in voluntary sport organizations, they have been found to be significantly associated with board member performance, effort, satisfaction, and commitment (Doherty \& Hoye, 2011; Sakires et al., 2009). However, these studies focused specifically on volunteers with long-standing, formal positions, such as board members, rather 
than on event volunteers. These two types of volunteers differ in several ways: Organization volunteers tend to be engaged for reasons that are different than those of event volunteers (Cuskelly et al., 2006); event volunteers' engagement is "sporadic and episodic" (Ralston, Downward, \& Lumsdon, 2004, p. 15) and of a relatively short duration in comparison to volunteers who are regularly involved with an organization, over a longer period of time; organization volunteers likely develop a more extensive relationship with the organization and other volunteers (Cuskelly et al., 2006); and, given the short-term and temporary nature of event volunteering, managers may have less time to adapt their role expectations with those individuals. Sport events may be characterized by several highly uncontrollable and uncertain dimensions, such as passionate spectators, intensive media coverage, and stakeholders with a diverse array of interests (Emery, 2003). In an auto-ethnographic account of the Vancouver 2010 Olympic Games volunteer experience, Kodama et al. (2013, p. 84) specifically reported that "the last minute and subsequently fast-paced nature of planning and communication [with the organizing committee]... was unnerving and a critical factor in my volunteer experience.” The current study extends knowledge of sport volunteer role ambiguity to the sport event context.

Factors that may be associated with role ambiguity in that context include role difficulty, training, and supervision. Role difficulty is a possible correlate of lack of clarity as sport event volunteers could be assigned tasks for which they have no previous experience (e.g., transportation coordination, results processing, merchandise sales) or specific skills (Ralston et al., 2004). Additionally, new and potentially complex tasks may be perceived to be quite challenging (Elstad, 1996), which may shape volunteers' understanding of what they are expected to do. For this very reason, a great deal of time and effort is spent on coordinating volunteer training and selecting appropriate supervisors to ensure things run smoothly (Costa, 
Chalip, \& Green, 2006; Gladden, McDonald, \& Barr, 2005; Shaw, 2009). Event volunteer training and further supervision are intended to enhance volunteers' understanding of their assigned tasks so that they contribute effectively to a successful event (Gladden et al., 2005). Thus, it is of interest to consider role difficulty, training and supervision as possible correlates of role ambiguity in this context. As noted above, role ambiguity may be expected to impact role effort, performance, and satisfaction (Brown \& Peterson, 1994; Doherty \& Hoye, 2011; Jackson \& Schuler, 1985; Sakires et al., 2009; Tubre \& Collins, 2000; Wolverton et al., 1999), with important implications of these correlates for sport event success. Further, volunteers' overall satisfaction and future volunteering intentions may be shaped by these experiences (Doherty, 2009).

Thus, the purpose of this study was to investigate volunteers' role ambiguity with a major multi-sport event (2012 Ontario Summer Games), and its association with perceptions of role difficulty, training, and supervision, and role performance, role effort, and role satisfaction. A further association with overall satisfaction with the volunteer experience and future intentions to volunteer were also examined. The findings make a three-fold contribution by (1) enhancing understanding of the sport event volunteer experience, (2) enhancing understanding of role ambiguity in the sport event volunteer setting, and (3) extending role ambiguity theory to this context. The findings also have implications for effective volunteer management.

\section{Theoretical Model}

Roles characterize behaviour that is expected of individuals who occupy a specific position in a group (Carron \& Eys, 2012; Katz et al., 1978). Kahn and colleagues (1964) advanced a role episode model and theorized that a role sender has certain expectations for the behaviour of the focal person in a given role and that the transmission and reception of those role 
responsibilities can be influenced by a number of factors in the organizational/industrial setting. The current study considers the perception of role ambiguity that may result from this encounter. Role ambiguity occurs when an individual lacks information that is pertinent to the fulfillment of his or her role (Sakires et al., 2009). More specifically, Kahn et al. (1964) defined work-related role ambiguity as an individual's perceived clarity regarding his or her job duties. Work-related task ambiguity occurs due to lack of information concerning the role an individual is expected to fulfill, including the scope of one's responsibilities, how to approach and fulfill one's tasks (means-ends knowledge), and what tasks take priority (Kahn et al., 1964; Sakires et al., 2009). Socio-emotional ambiguity occurs when individuals are unclear about how their work will be viewed by others in the group or organization (performance evaluation), and the consequences of the performance (or non-performance) of their tasks (performance outcomes) (Kahn et al., 1964; Sakires et al., 2009). Both global and multidimensional measures of role ambiguity have been found to be negatively related to motivation, satisfaction, and performance in a variety of paid and volunteer organizational settings (e.g., Doherty \& Hoye, 2011; Sakires et al., 2009; Tubre \& Collins, 2000). This study considers several antecedents and outcomes of role ambiguity that may be prevalent in the sport event volunteer setting.

\section{Role Difficulty and Role Ambiguity}

It has been suggested that role ambiguity will be particularly prevalent where there is high task complexity (Abdel-Halim, 1991; Tubre \& Collins, 2000). New and potentially complex tasks may be perceived as quite challenging, and this role difficulty may be expected to bear on role ambiguity. Allen and Shaw (2009) found that volunteers felt more competent when given the opportunity to use their existing skill set. The ability to use existing skills suggests some, and perhaps a sufficient, level of familiarity; therefore role ambiguity may be decreased as the task is 
perceived to be less difficult. Given the wide variety of tasks to be fulfilled, sport event volunteers may be assigned roles for which they have no previous experience (e.g., transportation coordination, results processing, merchandise sales). Thus, it is interesting to consider the relationship between perceived role difficulty and role ambiguity in this context.

\section{Training and Role Ambiguity}

In their study of volunteers at the Sunbelt Indy Carnival, Costa et al. (2006) examined the impact of pre-event training on volunteers' satisfaction. Volunteers were asked to evaluate their training based on the extent to which they found it to be unclear/clear, uninteresting/interesting, inconvenient/convenient, unimportant/important, not useful/useful and irrelevant/relevant. The more satisfied volunteers were with their opportunities to contribute during training sessions, the more positive were their evaluations of those sessions. Costa et al. suggested that when volunteers are directly involved with the training experience, the clarity of the material and their interest in it may be enhanced. Kodama et al. (2013) found that Olympic volunteer training was vital to effective performance by instilling confidence in the tasks to be done and understanding one's role within the larger event. Building on this, the link between perceived effectiveness of training and role ambiguity is considered.

\section{Supervision and Role Ambiguity}

Role supervision during an event is also an important factor to consider in terms of its potential effect on role ambiguity. Wright and Millesen (2008) argued that role ambiguity exists in large part because of lack of communication between employees and supervisors.

Communication helps establish the standards of behaviour by providing accurate role-related information regarding which behaviours employees should focus their attention and effort on (Wright \& Millesen, 2008). Feedback helps to achieve role clarity and avoid role ambiguity as it 
allows workers to realize whether they are achieving the desired goals in an appropriate manner (Wright \& Millesen, 2008). Schulz and Auld (2006) found that positive communication was negatively associated with the role ambiguity experienced by chairpersons and executive directors of voluntary sport organizations. Further, Jackson and Schuler (1985) concluded from a meta-analysis that receiving feedback from others is associated with low role ambiguity. The association between the perceived effectiveness of supervision and role ambiguity in the sport event volunteer context is considered here.

Several consequences of role ambiguity have also been identified in the volunteer and paid work contexts. Of particular interest to this study is the association between role ambiguity and perceived effort, performance, and satisfaction.

\section{Role Ambiguity and Effort}

Effort, a behavioural reflection of an individual's motivational state (Doherty \& Carron, 2003), is defined as how hard one works to fulfill the organization's goals (Blau, 1993;

Chelladurai, 2006). Role ambiguity may be expected to have a negative association with effort, as how hard one works may be influenced by whether the role is clearly understood. Brown and Peterson (1994) found that role ambiguity in general had a modest effect on effort in the work setting, while Sakires et al. (2009) found that multiple dimensions of role ambiguity accounted for $19 \%$ of the variance in effort among voluntary sport organization board members and staff. Further, ambiguity pertaining to performance outcomes was the best predictor of effort, followed by ambiguity pertaining to means-ends knowledge (Sakires et al., 2009). In their study of nonprofit board member role ambiguity, Wright and Millesen (2008) reported a significant negative relationship between role ambiguity and the executive director's evaluation of the board's 
engagement, assessed through a composite measure that included group effort, involvement, participation, and attendance.

\section{Role Ambiguity and Performance}

Role ambiguity has also been negatively associated with performance. Both self-reported performance and that indicated by a supervisor were found to have a negative association with role ambiguity (Ortqvist \& Wincent, 2006; Tubre \& Collins, 2000); when workers perceived their role to be poorly defined, they believed their performance to be subpar. Doherty and Hoye (2011) reported that multiple dimensions of role ambiguity explained $29 \%$ of total variance in volunteer board member performance, with scope of responsibilities the strongest predictor.

\section{Role Ambiguity and Satisfaction}

Job (or role) satisfaction, defined as “one's affective attachment to the job... in its entirety or with regard to particular aspects" (Tett \& Meyer, 1993, p. 261), has consistently been shown to have a negative relationship with role ambiguity in both the work and volunteer setting (Jackson \& Schuler, 1985; Sakires et al., 2009; Thompson et al., 1997; Wolverton et al., 1999). Ambiguity with respect to scope of responsibilities in particular was identified as the best predictor of satisfaction in the voluntary sport organization context (Sakires et al., 2009). In the sport event context, volunteers' enjoyment of their experience may be expected to hinge at least partly on their sense that they understand their assigned role (Costa et al., 2006).

To generate a further understanding of the sport event volunteer experience in the context of role ambiguity it is of interest to consider volunteer satisfaction overall and future intentions. These aspects are considered here.

\section{Volunteer Satisfaction and Future Intentions}


Research has identified factors that contribute to volunteers' positive experience with a sport event. In addition to social enrichment (Allen \& Shaw, 2009; Costa et al., 2006; Doherty, 2003; Elstad, 1996; Farrell et al., 1998; Green \& Chalip, 2004), research has found sport event volunteers' overall satisfaction to be positively associated with personal growth (Elstad, 1996), a sense of community contribution (Doherty, 2003; Elstad, 1996; Love et al., 2011), and celebration (Elstad, 1996). Interestingly, volunteers' overall satisfaction has been found to be negatively associated with factors that may be directly controlled by event organizers, including transportation, food, and accommodation, and job factors such as task overload and underload (Doherty, 2003; Elstad, 1996; Ralston et al., 2004). The current study adds to that body of work by examining the impact on overall satisfaction of volunteers' perceptions of their effort, performance, and satisfaction pertaining to their role in the event. These factors are examined in the context of volunteers' role ambiguity.

Understanding the sport event volunteers' overall satisfaction with their experience is important due to the relationship between satisfaction and intent to volunteer in the future. Cnaan and Goldberg-Glen (1991) argued that individuals will continue to volunteer as long as they feel rewarded and satisfied with their experiences as a whole. A number of studies in the sport event context have examined future intentions to volunteer; however, only a few of those have established an empirical link between volunteers' event experience and their future intentions (Doherty, 2009; Downward \& Ralston, 2006; Love et al., 2011). Of particular relevance to the current study, Love et al. (2011) found that volunteers' satisfaction with their experience at a PGA event was predictive of their intent to volunteer again. The current study adds to this research by considering the impact of volunteers' overall satisfaction on their further intentions to volunteer; again, within the context of role ambiguity and its correlates. 
The relationships of interest are illustrated in a theoretical model developed for this study (Figure 1), and are addressed in the following hypotheses derived from the extant research: Hypothesis 1: High perceived role difficulty will predict high role ambiguity.

Hypothesis 2: Perceived effective event volunteer supervision will predict low role ambiguity. Hypothesis 3: Perceived effective event volunteer training will predict low role ambiguity. Hypothesis 4: High role ambiguity will predict low perceived effort.

Hypothesis 5: High role ambiguity will predict low perceived role performance.

Hypothesis 6: High role ambiguity will predict low role satisfaction.

Hypothesis 7: High perceived role effort will predict high overall satisfaction with the volunteer experience.

Hypothesis 8: High perceived role performance will predict high overall satisfaction with the volunteer experience.

Hypothesis 9: High role satisfaction will predict high overall satisfaction with the volunteer experience.

Hypothesis 10: High overall satisfaction will predict high future intentions to volunteer.

[insert Figure 1 here]

\section{Method}

\section{Participants}

The Ontario Summer Games is a multi-sport event held in a different community every two years. The 2012 Ontario Summer Games was held in 22 competition venues in several communities in and around the Greater Toronto Area from August 16-19. The sample comprised the population of about 1,000 volunteers who were involved with the delivery of the Games. A total of 328 volunteers participated in the study by completing an online survey after the event. 
Of the respondents, $40 \%$ were male and $60 \%$ were female. The majority were 25 to 49 years of age (45\%); $12 \%$ were 14 to 17 years of age, $10 \%$ were 18 to 24 years of age, and $33 \%$ were 50 years of age or older. The organizing committee only kept data on the number of youth volunteers (14-17 years; L. Davidson, personal communication, October 3, 2012) and the findings indicate the study sample was fairly consistent with the Games volunteer population in that category (17\%). Most respondents had completed at least some college education (55\%), with $24 \%$ having received post graduate education. Respondents tended to be employed (53\%), while $24 \%$ were students and $23 \%$ were unemployed, retired or homemakers. Most respondents were personally involved in sport (68\%), and had other volunteer experience outside of the 2012 Ontario Summer Games (90\%). While a demographic profile of the Games volunteers is not available, the sample generally resonates with other known profiles of sport event volunteers (e.g., Doherty, 2003), with the exception that the current sample was slightly less likely to be employed and more likely to be personally involved in sport.

Games volunteers were expected to attend one of five three-hour, in-person orientation sessions to familiarize themselves with the Games as well as any role-specific duties expected of them. While these sessions were indicated as "mandatory" in all correspondence with volunteers, it was acknowledged that volunteers in certain roles were allowed to be involved without that orientation, and all volunteers were ultimately given an option of viewing the orientation session online (L. Davidson, personal communication, July 16, 2012). Volunteers received a 22-page Ontario Summer Games Volunteer Handbook which included a "Volunteer Acknowledgement" of the terms of the volunteers' general role in the Games, as well as "Policies and Guidelines" for expected behavior. A t-shirt uniform was handed out at volunteers' first of at least two four-hour shifts they were required to complete. Any venue and role-specific training required was also 
carried out at the first shift, by a Volunteer Manager. The 1,000 Games volunteers contributed over 15,000 hours to the event (Toronto, 2013), in roles across 13 different areas that ranged from registration, to accommodations, to IT and equipment.

\section{Measures}

Role ambiguity. Role ambiguity was assessed using the Multidimensional Measure of Organizational Role Ambiguity (MMORA), developed by Sakires et al. (2009) in the context of volunteer sport organizations. The 24-item MMORA represents three dimensions of role ambiguity: Scope of responsibilities (understanding what tasks must be completed), Means-ends knowledge (understanding how to fulfill one's responsibilities), and Performance outcomes (understanding the consequences of one's performance and how one's performance is evaluated). Doherty and Hoye (2011) found support for the factorial validity $(\mathrm{CFI}=.96, \mathrm{TLI}=.95$, RMSEA $=.08$ ) of the three dimensions of the MMORA in their study on board member performance in nonprofit sport organizations as well as adequate reliability for all three dimensions (means-ends knowledge, $\alpha=.83$; scope of responsibilities, $\alpha=.88$; performance-outcomes, $\alpha=.91$ ), albeit with a reduced number of items.

The MMORA was adapted slightly to the event volunteer context in the current study. For example, participants were asked how clearly they understood "how my work related to the overall objectives of the Games" and "what difference my performance made to the Games." Also, two items that were deemed to be overly redundant with several other items in the performance outcomes subscale were removed, serving to reduce the length of that subscale to nine items ("the effect of failing to carry out my responsibilities", "the effect of successfully carrying out my responsibilities"). The role ambiguity measure for the current study comprised 22 items. Participants were asked to indicate, using a seven-point Likert-type scale $(1=$ 
completely disagree to $7=$ completely agree), the extent to which they agreed that they "clearly understood" each of the 22 items. Scope of responsibilities and performance outcomes ambiguity were each measured using nine items, while four items measured means-ends knowledge ambiguity. Sample items are indicated in Table 1. As the items measure role clarity, they were reverse coded prior to data analysis..

Role difficulty. A six-item measure was developed in line with role difficulty as a reflection of the extent to which an individual is able to satisfy the demands of a task-based role according to the resources that he or she brings to the tasks (Robinson, 2001). Tasks which are new, complex or require much effort or skill may challenge or deplete the individual's resources, and make their role difficult to fulfill. Accordingly, participants were asked to indicate on a seven-point Likert scale $(1=$ completely disagree to $7=$ completely agree $)$ their agreement with six items, including: (1) "My tasks and responsibilities were quite new to me," (2) "I had a lot of different tasks I was responsible for," (3) "My assignment was quite difficult for me," (4) "I had to use a lot of skills I had never used before," (5) My role required a lot of effort on my part, and (6) "The tasks I had to do were quite challenging." The content validity of this, and all newly developed measures in the study, was determined independently and then jointly by the research team members with respect to the constitutive definition of the variable.

Role training. A six-item measure for volunteer role training was adapted from the items that Costa et al. (2006) used in their study of the impact of training on event volunteers' satisfaction. Costa et al. (2006) asked participants to indicate the extent to which they found their training to be 'unclear or clear', 'uninteresting or interesting', 'inconvenient or convenient', 'unimportant or important', 'not useful or useful' and 'irrelevant and relevant'. The present study used one word of each of the pairings and asked respondents to indicate their level of agreement 
or disagreement with each item by using a seven-point Likert scale $(1=$ completely disagree to 7 = completely agree). Thus, respondents assessed their role training by indicating the extent to which they agreed or disagreed with items such as "training was interesting", "training was clear", "training was convenient", and so on.

Role supervision. A four-item measure was developed to assess volunteer role supervision within the context of the present study. Respondents were asked to rate the following items using a seven-point Likert scale $(1=$ completely disagree to $7=$ completely agree $)$ : "My supervisor gave me guidance to do my tasks", (2) "My supervisor gave me support during the Games", (3) "My supervisor was approachable”, and (4) "My supervisor was accessible”.

Role effort. A three-item measure of volunteer role effort was adopted from Doherty's (2003) study of Canada Games volunteers. Effort can be considered as how hard one works to fulfill the organization's goals, taking into account both direction and intensity (Blau, 1993; Chelladurai, 2006; Sakires et al., 2009). In the present study, effort was measured by asking participants to rate on a seven-point Likert scale how much they agree or disagree $(1=$ completely disagree and 7=completely agree) with the following three items, "I worked hard on my assigned tasks" and "I did all I could towards fulfilling my role" and "I did my best to carry out my responsibilities".

Role performance. A four-item measure was developed based on the definition of role performance as behavior that is consistent with role expectations (Carron \& Eys, 2012). Respondents were asked to rate, on a seven-point Likert-type scale (1=strongly disagree and 7=strongly agree), their agreement with: (1) "I successfully completed my assigned tasks," (2) "I did a good job," (3) "I performed my role as expected," and (4) "My responsibilities were satisfactorily fulfilled." 
Role satisfaction. A three-item measure was developed to determine volunteer role satisfaction. Participants were asked to indicate their level of satisfaction or dissatisfaction on a seven-point Likert-type scale $(1=$ very dissatisfied to $7=$ very satisfied $)$ with three items that reflect their role within the 2012 Ontario Summer Games: (1) "My volunteer assignment with the Games," (2) "The tasks I was given to do", and (3) "My volunteer role."

Overall satisfaction. Three items that Doherty (2003) developed to measure satisfaction with the volunteer experience were adopted. The current study asked participants to rate their level of satisfaction or dissatisfaction with the following items on a seven-point Likert-type scale $(1=$ very dissatisfied to $7=$ very satisfied $)$. Items included: ( 1$)$ "The overall volunteer experience," (2) "My personal involvement with the Ontario Summer Games," and (3) "My experience at the Games."

Future volunteer intentions. A single item from Doherty's (2003) study of Canada Games volunteers was adopted for this study. Participants were asked to indicate on a sevenpoint Likert-type scale anchored by 1 (definitely would not volunteer) and 7 (definitely would volunteer) their likelihood of becoming involved in a major sports event in the future.

\section{Procedure}

Ethics approval for the study was secured from the research ethics board at the authors' university. The 2012 Ontario Summer Games Organizing Committee agreed to distribute an email directly to the volunteers after the close of the Games, inviting them to a link to an online survey at a secure website. Following the recommendations of Dillman (2007), the Organizing Committee distributed reminder emails one week and two weeks following the initial contact.

\section{Results}


To test the hypothesized relationships a two-step structural equation modelling (SEM) approach was undertaken (Kline, 2005). The analyses were performed via Amos 20.0 (Arbuckle, 2011). In the first step, the measurement model was examined to assess construct reliability as well as convergent and discriminant validity. In the second step, the structure of the hypothesized model was examined for overall model fit and for the relationships among the variables.

\section{Measurement Model}

A confirmatory factor analysis (CFA) was conducted to test a measurement model that included all the variables of interest, with two exceptions: The single item measure of future intentions was excluded (cf. Kline, 2005). As well, the data revealed that $20 \%$ of respondents did not take part in formal training and so were not able to provide any perceptions about it in the survey. This resulted in too much missing data to be replaced (Tabachnick \& Fidell, 2013), and so it was not possible to examine this variable (or consider Hypothesis 3 ) in further multivariate analyses. To assess model fit, the chi-square statistic, comparative fit index (CFI; Bentler, 1990), Tucker-Lewis Index (TLI; Tucker \& Lewis, 1973), normative fit index (NFI; Bentler \& Bonett, 1980), and SRMR (Bentler, 1995) were considered. A non-significant chi-square statistic signifies that the model correlation matrix is not significantly different from the observed correlation matrix, and therefore indicates that the model is a good fit (Schumacker \& Lomax, 2010; Tabachnick \& Fidell, 2013). For the CFI, NFI, and TLI, values above 90 represent good fit (Bentler, 1990), while values less than .08 for the SRMS represent good fit (Bentler, 1995; Browne \& Cudeck, 1993).

With all but one of the fit indices for the CFA failing to meet acceptable levels, the model demonstrated poor fit; $\chi^{2}(909)=3009.4, p<.001, \mathrm{CFI}=.86, \mathrm{TLI}=.85, \mathrm{NFI}=.81, \mathrm{SRMR}=$ .065. A subsequent review of the model output (Todman \& Dugard, 2007) revealed very high 
inter-correlations among the role ambiguity variables $(>.90)$, indicating problems with multicollinearity (Kline, 2005). With such failure to establish discriminant validity, Kline suggests that one variable may be eliminated or all may be combined. It is not clear from the output, and there is no theoretical basis to indicate, which variable should be retained; however there is a theoretical basis for the multidimensional rather than unidimensional representation of role ambiguity. As such, the possibility of an alternate measurement structure underlying the role ambiguity items was explored.

\section{Exploratory Analysis}

Principal components analysis may be used to assess the nature of redundant variables for inclusion in further analysis when there is a theoretical basis to do so (Tabachnick \& Fidell, 2013). Previous research has demonstrated that such an approach to re-specify a model can be beneficial (Gammage et al., 2004; Haase \& Prapavessis, 2004; Sakires et al., 2009), particularly when a measure is used in a new context, such as in the current study, where it may have a slightly different meaning and thus scale configuration (DeVellis, 2012). Thus, principal-axis factoring with oblique (direct oblimin) rotation was used to re-specify the role ambiguity measure. Oblique rotation was chosen as correlations between the factors were expected (Tabachnick \& Fidell, 2013).

Two measures were examined to determine whether it was appropriate to interpret the results of the PCA. Bartlett's test of sphericity, used to measure item interdependence, was significant $\left(\chi^{2}=8097.83, \rho<.001\right)$, and the Kaiser-Meyer-Olkin measure of sampling adequacy was acceptable at .96, and thus the factor analysis results were interpreted (Tabachnick \& Fidell, 2013). Factors with eigenvalues equal to or greater than 1.0 were considered (Tabachnick $\&$ Fidell, 2013). Items with a factor loading of .50 and above are considered to be good, and thus 
were retained (Tabachnick \& Fidell, 2013). One item that loaded onto more than one factor within 0.1 was excluded due to lack of factor purity. One additional item ("how to prioritize the multiple expectations of my position") was deleted as it did not fit conceptually with the other items with which it loaded. Nunnally and Bernstein (1994) argued that the findings should make theoretical sense, and researchers should not blindly accept results.

The analysis produced a final 2-factor structure with a total of 20 items that met the specified criteria. The first factor was labelled "performance outcomes ambiguity," comprising 15 items that refer to participants' understanding of what difference they made to the event and where they fit in. The second factor was labelled "means-ends/scope ambiguity," containing five items that represent how clear volunteers were regarding what tasks they had to do and how they had to do them. Together, performance outcomes and means-ends/scope ambiguity accounted for $71.75 \%$ of total variance. Table 1 portrays the item factor loadings, eigenvalues, and variance.

[insert Table 1 about here]

\section{Psychometric Properties}

Cronbach's alpha coefficients and scale inter-correlations were calculated to test the reliability and independence of the variables. Cronbach's alpha values above .80 are considered to be an acceptable indicator of... (Lance, Butts, \& Michels, 2006), while bivariate scale intercorrelations above .90 are evidence of multicollinearity (Kline, 2005; Tabachnick \& Fidell, 2013). Acceptable levels of internal consistency were demonstrated by both the performance outcomes subscale $(\alpha=.97)$ and the means-ends/scope subscale $(\alpha=.92)$. With regard to the remaining scales, internal consistencies were also considered acceptable $(>.80)$ for the measures of role performance, role difficulty, supervision, role satisfaction, and overall satisfaction (see Table 2). The three items representing event volunteer effort produced an alpha of .69, indicating 
poor reliability. This was improved to .81 with the removal of the item "I worked hard on my assigned tasks". Thus, the final measure of effort comprised a reliable two-item scale that was determined to be a valid representation of direction and intensity (cf. Blau, 1993; Chelladurai, 2006). Bivariate correlations among the variables revealed no issues with multicollinearity (see Table 2).

\section{Structural Model of Correlates of Volunteer Role Ambiguity}

Given the outcome of the measurement model analysis, and subsequent support for the observed variables, path analysis through SEM was used to further examine the relationships between variables and test the theoretical model in Figure 1 (Kline, 2005; Schumacker \& Lomax, 2010; Todman \& Dugard, 2007). Mean values of each observed variable were used in the model. The critical values indicating model fit noted earlier were applied to the structural model.

Model 1. The full model (Figure 2) contained all of the variables of interest (with training excluded, as noted above, and future intentions included), and reflected the hypotheses to be tested. It made conceptual and theoretical sense to co-vary the two dimensions of role ambiguity. Allowing the observed residuals in the dependent variables to co-vary may also account for some of the variance not explained through the paths (Tabachnick \& Fidell, 2013). The estimated model did not fit the data, $\chi^{2}(20)=160.0, p<.001, \mathrm{CFI}=.901, \mathrm{NFI}=.890, \mathrm{TLI}=.822, \mathrm{SRMR}=$ .09 .

Model 2. A review of the fit indices and parameters was undertaken to help guide modification of a model that might produce better fit (Schumacker \& Lomax, 2010). The standardized parameter estimates (SPE) indicated that six of the regression paths were not significant $(p>.01)$. Given that the objective in modeling is to develop a good-fitting model, which may be nested in a larger model, non-significant parameters can be deleted (Kline, 2005). 
Five paths ranged in value from -.01 to $.07(\mathrm{p}>.01)$ and thus were determined to not be engaged with the model variables and so were removed. This led to the removal of role difficulty as a possible correlate of role ambiguity, performance outcomes ambiguity as a correlate of role effort and role performance, and effort as a correlate of overall satisfaction. An additional nonsignificant path $(-.13, \mathrm{p}>.01)$, between means-ends/scope ambiguity and role satisfaction, was identified and determined to be compromising model fit. Notably, another relatively weak path (between performance and overall satisfaction) was identified, although it was significant (.09, $\mathrm{p}$ $<.01)$. Given that it is the performance of volunteers that is vital to the success of sport events (Cuskelly et al., 2006), and given the non-significance of the means-ends/scope ambiguity and role satisfaction path, it was decided to remove this path and retain the role performance and overall satisfaction path for further consideration. The model was then re-estimated.

The modified model that was tested further specified that supervision predicted both performance outcomes and means-ends/scope ambiguity, and performance outcomes ambiguity predicted role satisfaction. The model also specified that role satisfaction predicted overall satisfaction, and overall satisfaction predicted future intentions. Additionally, the model specified that means-ends/scope ambiguity predicted role performance and effort. All of the regression paths were significant $(p<.001)$ and in the expected directions. However, the model did not fit the data, $\chi^{2}(19)=154.2, p<.001, \mathrm{CFI}=.903, \mathrm{NFI}=.892, \mathrm{TLI}=.857, \mathrm{SRMR}=.09$.

Model 3. Upon further review of the model fit and modification indices, a very high index (53.54) was identified for role effort and role performance, suggesting that adding a parameter between these variables may be meaningful (Schumacker \& Lomax, 2010). An association between volunteers' perceived effort and performance may not be surprising, and the bivariate correlation (Table 2) indicated a significant relationship. Thus, the error residuals of 
role effort and performance were allowed to covary and the model was re-estimated. The final model (Figure 3) yielded a good fit, $\chi^{2}(18)=76.3, p<.001, \mathrm{CFI}=.958, \mathrm{NFI}=.946$; TLI $=.935$, $\mathrm{SRMR}=.07$. A further $\chi^{2}$ difference test confirmed the significantly improved model fit $\Delta \chi^{2}(-1)$ $=77.9$ (Tabachnik \& Fidell, 2013).

\section{Discussion}

The present study provides insight into the relationship between volunteers' perceptions of ambiguity with their role with the 2012 Ontario Summer Games and correlates of that ambiguity. It specifically provides insight into the distinct dimensions of performance outcomes ambiguity and means-ends/scope ambiguity and their differential association with these critical antecedents and outcomes. The findings are, of course, specific to the context of study, however they extend understanding of the correlates of ambiguity, and implications arising from those findings may be extended to similar major multi-sport events. The original 3-factor model of role ambiguity derived by Sakires et al. (2009) in the sport volunteer organization setting was not supported in the present context. Rather, performance outcomes ambiguity comprised a combination of items from Sakires et al.’s (2009) performance outcomes and scope of responsibilities dimensions which, together, represent volunteers' understanding of where they fit into the event as a whole, what difference their role made, and what impact they had on the event. The second dimension, means-ends/scope ambiguity, reflects volunteers' understanding of what tasks they had to do and how they had to do them. Although Kahn et al. (1964) theorized that means-ends knowledge and scope of responsibilities are distinct dimensions of role ambiguity, it may be that knowing what one is expected to do in one's role is intertwined with knowing how to fulfill it, at least in the volunteer context (cf. Sakires et al., 2009). In the sport event volunteer context in particular, volunteers are often assigned menial tasks (Costa et al., 
2006) that take place over a relatively short time period; therefore, knowing what tasks are supposed to be done may be tantamount to knowing how to complete them. On average, participants in the current study only slightly disagreed that their roles were difficult (see Table 2) - thus perhaps not exactly menial in their eyes - yet the scope of the task itself, and how to fulfill it, were aligned for these volunteers. These findings suggest there may be something about the nature of volunteer roles, in the organization and event context, which engenders a complementary understanding of both what and how tasks should be done.

The current study also provides insight into several possible antecedents of sport event volunteer role ambiguity. Role difficulty was not found to be a significant predictor of either dimension of role ambiguity, contrary to Hypothesis 1. Previous research suggests that role ambiguity is particularly meaningful where there is high task complexity (Abdel-Halim, 1991; Tubre \& Collins, 2000), although that work is based in the paid employee context. Nonetheless, while it seems reasonable that volunteers understood where they fit in (performance outcomes ambiguity), regardless of any perceived difficulty of their role, the absence of a link between means-ends/scope ambiguity and role difficulty may be more surprising. Perhaps volunteers' understanding of what they were expected to do and how to fulfill their tasks was not affected even if their roles required the use of new skills or were perceived to be challenging because of their previous volunteering experience. Although the nature of that experience was not measured here, it may have been a source of perceived competence and confidence for their Games roles. This possibility may have implications for the recruitment of experienced volunteers for major sport events, and warrants further investigation.

Hypothesis 2 was supported as perceived effective event volunteer supervision was found to predict lower role ambiguity; in other words, volunteers who felt their supervisor was 
accessible and approachable, and provided guidance and support, were less likely to experience either means-ends/scope or performance outcomes ambiguity. This finding is consistent with previous research in both the paid and volunteer settings which found that receiving positive communication and feedback from others, such as a supervisor, is associated with lower role ambiguity (Jackson \& Schuler, 1985; Schulz \& Auld, 2006; Wright \& Millesen, 2008). Parent, Olver and Seguin (2009) noted that in the major sport event context supervisors must be able to clarify different roles as subordinates look to them for necessary support and instruction. Positive perceptions of supervision appeared to be a slightly stronger predictor of performance outcomes ambiguity $(\beta=-.69)$ than means-ends/scope ambiguity $(\beta=-.55)$ in the current study. It is notable that having a supervisor who was perceived to be accessible and supportive was directly associated with volunteers' understanding of where they fit into the event more so than the nature of their task and how to do it, although this was also meaningful.

The final model indicated support for Hypotheses 4 and 5, although only meansends/scope ambiguity significantly predicted role effort and role performance. The findings are consistent with previous research, which has found role ambiguity to be associated with decreased effort and performance in both the work and volunteer settings (Brown \& Peterson, 1994; Hoye \& Doherty, 2011; Ortqvist \& Wincent, 2006; Sakires et al., 2009; Tubre \& Collins, 2000). However, the observed association with this particular type of role ambiguity suggests that the better understanding volunteers have specifically about what they are expected to do and how, the more likely they are to do their best to carry out their role, and feel that they perform well. The findings further suggest that this is more critical to volunteers' effort and performance than knowing what difference their contribution makes (performance outcomes ambiguity). While means-ends ambiguity was also a significant predictor of effort in Sakires et al.'s (2009) 
study, they noted that performance outcomes ambiguity appeared to be a more meaningful predictor, according to the respective coefficients. The slightly different findings may be a function of the context of a large community event, where people want to make a contribution (Bang \& Chelladurai, 2009; Doherty, 2003; Love et al., 2011) and so volunteers put in their time and good effort regardless of a clear understanding of where they fit into the whole event. It may also be a function of the short-term nature of the event, where volunteers work hard regardless of understanding their performance outcomes because they know their contribution is only for a short, defined period of time. Both of these explanations may further distinguish the nature of sport organization and event contexts, and the impact of role ambiguity there.

Consistent with previous research (Jackson \& Schuler, 1985; Sakires et al., 2009; Thompson et al., 1997; Wolverton et al., 1999), Hypothesis 6, proposing that role ambiguity would predict role satisfaction, was also supported by the findings. However, only performance outcomes ambiguity explained unique variance in this factor. The finding suggests that knowing what difference one's role fulfillment makes to the event and where one fits in may be vital to event volunteers' satisfaction with their role. In contrast, Sakires et al. (2009) found that scope of responsibilities ambiguity was the strongest predictor of satisfaction in the voluntary sport organization setting. The findings appear to further distinguish correlates of ambiguity in different volunteer contexts such that understanding one's contribution to "a one-time or infrequently occurring event" (Getz, 2007, p. 16) that has "a unique and all-consuming climax untypical of other [organization activities]" (Mules, 2004, p. 95) is linked with volunteers' satisfaction with their role whereas understanding the specifics of their role is not. In contrast, role satisfaction in the organization setting is more strongly associated with specifics of a 
volunteer's regular, ongoing role than an understanding of where they fit into the big picture (Sakires et al., 2009).

The final model also revealed that volunteers' role performance and role satisfaction were associated with overall satisfaction with the Games experience. Thus, hypotheses 8 and 9 were supported; however, Hypothesis 7 (effort and overall satisfaction) was not. The findings indicate that volunteers' perception of the effort they contributed had no significant relationship with their overall satisfaction with the Games. This too may be a function of the context, where doing their best to fulfill their role may not be linked with the volunteers' overall Games experience because of the short term and temporary nature of their involvement in the event. Nonetheless, given that it is a significant correlate of role ambiguity, consideration of the impact of perceived effort on further individual and event outcomes is warranted. In contrast, volunteers' sense of how good a job they did in their specific role, and their satisfaction with that role, were associated with their overall positive assessment of the Games experience. Notably, role satisfaction appeared to be a stronger predictor $(\beta=.75)$ of overall satisfaction than role performance $(\beta=.13)$. The findings suggest that volunteers' overall satisfaction was a more meaningful correlate of satisfaction with their role, which is associated with their sense of where they fit into the Games and what difference they made to the event. In comparison, volunteers' overall satisfaction was a significant but seemingly relatively less meaningful correlate of role performance that is associated with understanding one's role and how to do it. These findings add to the body of knowledge on correlates of event volunteer satisfaction and broaden understanding of factors pertaining to volunteers' role experience that impact on that overall satisfaction. Notably, both forms of role ambiguity factored into this dynamic. 
Consistent with previous research (Love et al., 2011), the hypothesis that overall satisfaction will predict future intentions to volunteer at another major sport event (Hypothesis 10) was supported. Research has found that after volunteering at a sport event, individuals are slightly more likely to volunteer in the future (Doherty, 2009; Downward \& Ralston, 2006; MacLean \& Hamm, 2007), and particularly at another major sport event (Doherty, 2009). The findings of the current study support that individuals will continue to volunteer to the extent that they feel satisfied with their overall experiences (Cnaan \& Goldberg-Glen, 1991; Love et al., 2011). As noted above, the final model identified role performance and role satisfaction as predictors of that overall satisfaction, and the association of role ambiguity with those factors. The current study contributes to the body of work that addresses an important legacy of sport events which is to promote the continued volunteering of individuals, at future events and in the community, and understanding factors that impact on that (e.g., Doherty, 2009; Love et al., 2011). While overall satisfaction explains a notable proportion of the variance in future intentions $(\beta=.43)$, participants' relatively high intention to volunteer for another major sport event is presumably only partially attributed to their current Games experience. The large majority of study participants $(90 \%)$ had previous volunteer experience of some kind and thus may represent a cohort that is likely to indicate an intention to (continue to) volunteer under any circumstances. Further, as Doherty (2009) noted, "other factors can certainly be expected to influence [future event volunteering]" (p. 201). The current study, nonetheless, advances understanding of the link between volunteers' event experience and their future volunteering intentions, and specifically within the context of any role ambiguity.

Taken together, the findings highlight several variations in the correlates of the different types of role ambiguity examined here, distinguishing the potential impact of sport event 
volunteers knowing what to do in their role and how to do it, versus knowing where they fit into the big picture and what difference their contribution makes overall. These differences may also extend to distinguishing volunteers in the sport event versus organization context, where volunteers are typically involved temporarily and for the short-term versus involved regularly and for a longer duration, respectively. Implications for event volunteer management and directions for future research are discussed below.

\section{Implications for Sport Event Organizers}

To the extent that the findings are generalizable to other similar major sport events, they suggest that role ambiguity has the potential to be problematic for sport event organizers, given its significant negative associations with role effort, performance and satisfaction (and the further association of role performance and satisfaction with overall satisfaction). In general, the findings highlight the importance of ensuring that volunteers understand what their responsibilities are and how to meet them, and how they fit into the event. These may be expected to be associated with higher levels of effort and performance, ensuring that important tasks get successfully completed, and positive feelings about those tasks, which may be expected to be associated with greater overall satisfaction and further intentions to volunteer at another major sports event. As such, the impact of the event on the community may extend beyond its fundamental focus on the successful delivery of the competition itself, and provide a strong volunteer legacy (Doherty, 2009; Downward \& Ralston, 2006; Love et al., 2011).

More specifically, given the differential impact of the two dimensions of role ambiguity, there may be implications for addressing each form. For example, ensuring that volunteers are aware of how their role relates to the overall objectives of the event and the impact of doing what is expected may be effective in reducing performance outcomes ambiguity, but less effective in 
reducing means-ends/scope ambiguity regarding exactly what one is supposed to do and how. The former might be the kind of message delivered through generic motivational statements from the organizing committee about the importance of volunteers to the event (cf. Shaw, 2009). Improving clarity with regard to what one is supposed to do and how may require the provision of more detailed information and support, such as through formal job descriptions that outline volunteers' role responsibilities, and opportunities for role-specific clarification along the way. While such practices may be a standard part of major sport events, the findings highlight the implications for the management of different types of role ambiguity through corresponding forms of supervision and support. Further, if a particular goal of an event is volunteer overall satisfaction, and a legacy of future volunteers, the findings suggest that a particular focus on generating role satisfaction among volunteers is important, which may be facilitated by ensuring they are clear about where they fit in and what difference they make to the event.

\section{Recommendations for Future Research}

The current study prompts several directions for future research. Building on previous multidimensional role ambiguity research in the sport organization setting (Doherty \& Hoye, 2011; Sakires et al., 2009), the present study found support for a two-dimensional model of role ambiguity in the sport event volunteer context. As this was the first known attempt to quantify role ambiguity in the sport event volunteer setting, it is necessary to cross-validate the findings with a new sample (DeVellis, 2012; Tabachnik \& Fidell, 2013). It should be acknowledged that variables where the error residuals shared significant covariance suggest that another important factor not measured in the present study may also add significant variance to the model. Thus, future research should also assess theoretically plausible factors that may contribute to this model. At the same time, variables with high reliability coefficients (such as the role ambiguity 
factors here) suggest redundant items which may be reconsidered as part of scale refinement. Additionally, validation of the role ambiguity instrument in other event volunteer settings could broaden its relevance while providing further insight into the nature and correlates of role ambiguity of volunteers. Importantly, a multidimensional perspective allows for the consideration of unique relationships between different types of ambiguity and key correlates.

There were several indications that correlates of role ambiguity vary for ongoing, organizational volunteers, as indicated in Doherty and Hoye (2011) and Sakires et al. (2009), and episodic, event volunteers, as indicated in the current study. The contrasting findings prompt a further comparative investigation of role ambiguity in those respective contexts, perhaps by more in depth, qualitative methods. Such an investigation may also shed light on the nature of volunteer roles, in both contexts, that helps explain why understanding what to do closely aligns with how to do it. Additionally, it would be of interest to consider the hypothesized, and observed, relationships in the current study with respect to future intentions to volunteer in ongoing (as opposed to one-time, major) sport events and other community event settings.

The possible limitations of the generalizability of the study findings have already been noted. Another limitation pertains to the inability to fully test the hypothesized model, and specifically the exclusion of training as a possible correlate of role ambiguity, with implications for future research. As not all volunteers completed training, the current study could not investigate this relationship in depth. Training is a fundamental aspect of major events (Costa et al., 2006; Gladden et al., 2005), and has been identified elsewhere as vital to volunteer learning, competence, and confidence (Kodama et al., 2009; Shaw, 2009). Thus, its link with role ambiguity warrants further investigation. 
Finally, building on the implication for practice regarding differential supervision for the different forms of role ambiguity, possible nuances of supervision and their association with role ambiguity may be explored. For example, research could investigate the presence and impact of different types of leadership or different messages pertaining to volunteers in the sport event context. As training and supervision are both areas in which event organizers have a considerable amount of control, further analysis of the association of these variables with role ambiguity may reveal important implications for effective event volunteer management. 


\section{References}

Abdel-Halim, A. A. (1981). Personality and task moderators of subordinate responses to perceived leader behavior. Human Relations, 34, 73-88.

Allen, J., \& Shaw, S. (2009). “Everyone rolls up their sleeves and mucks in’': Exploring volunteers' motivation and experiences of the motivational climate of a sporting event. Sport Management Review, 12, 79-90.

Arbuckle, J. L. (2011). Amos (20.0). Crawfordville, FL: Amos Development Corporation.

Bang, H., \& Chelladurai, P. (2009). Development and validation of the volunteer motivations scale for international sporting events (VMS-ISE). International Journal of Sport Management and Marketing, 6(4), 332-350.

Bentler, P. M. (1990). Comparative fit indices in structural equation modelling. Psychological Bulletin, 107, 238-246.

Bentler, P. M. (1995). EQS structural equation programs manual. Enchino, CA: Multivariate Software.

Bentler, P. M., \& Bonnett, D. G. (1980). Significance tests and the goodness-of-fit in the analysis of covariance structures. Psychological Bulletin, 88, 588-606.

Blau, G. (1993). Operationalizing direction and level of effort and testing their relationships to individual job performance. Organizational Behavior, 55, 152-170.

Brown, S. P., \& Peterson, R. A. (1993). Antecedents and consequences of salesperson job satisfaction: Meta-analysis and assessment of causal effects. Journal of Marketing Research, 30(1), 63-77 
Browne, M. W., \& Cudeck, R. (1993). Alternative ways of assessing model fit. In K. A. Bollen \& J. S. Long (Eds.), Testing structural equation models (pp. 136-162). Newbury Park, CA: Sage.

Carron, A. V., \& Eys, M. A. (2012). Group dynamics in sport (4th ed.). Morgantown, W.V: Fitness Information Technology.

Carver, J. (1997). Boards that make a difference: A new design for leadership in non-profit and public organizations ( $2^{\text {nd }}$ ed.). San Francisco: Jossey-Bass.

Chelladurai, P. (2006). Human resource management in sport and recreation (2nd ed.), Champaign, IL: Human Kinetics.

Cnaan, R. A., \& Goldberg-Glen, R. S. (1991). Measuring motivation to volunteer in human services. Journal of Applied Behavioral Sciences, 27, 269-284.

Costa, C., Chalip, L., \& Green, B. C. (2006). Reconsidering the role of training in event volunteers' satisfaction. Sport Management Review, 9, 165-182.

Cuskelly, G. C., Hoye, R., \& Auld, C. (2006). Working with volunteers in sport: Theory and practice. Abingdon, UK: Routledge.

DeVellis, R. F. (2012). Scale development: Theory and applications $\left(2^{\text {nd }}\right.$ ed.). Thousand Oaks, CA: Sage.

Dillman, D. A. (2007). Mail and internet surveys: The Tailored Design Method. (2nd ed.) Hoboken, NJ: Wiley.

Doherty, A. (2003). A study of the volunteers of the 2001 Alliance London Jeux du Canada Games. London, ON: The University of Western Ontario.

Doherty, A. (2009). The volunteer legacy of a major sport event. Journal of Policy Research in Tourism, Leisure, and Events, 1(3), 185-207. 
Doherty, A., \& Carron, A. V. (2003). Cohesion in volunteer sport executive committees. Journal of Sport Management, 17, 116-141.

Doherty, A., \& Hoye, R. (2011). Board member performance in nonprofit sport organizations. Nonprofit Management \& Leadership, 22(1), 108-128.

Downward, P., \& Ralston, R. (2006). The sports development potential of sports event volunteering: Insights from the XVII Manchester Commonwealth Games. European Sport Management Quarterly, 6, 333-351.

Elstad, B. (1996). Volunteer perceptions of learning and satisfaction in a mega-event: The case study of the XVII Olympic Winter Games in Lillehammer. Festival Management and Event Tourism, 4, 75-83.

Emery, P. (2003). Sports event management. In L. Trenberth (Ed.), Managing the business of sport (pp. 269-292). Palmerston North: Dunmore Press.

Eys, M. A., Carron, A. V., Beauchamp, M. R., \& Bray, S. R. (2005). Athlete's perceptions of the sources of role ambiguity. Small Group Research, 36(4), 383-403.

Farrell, J. M., Johnston, M. E., \& Twynam, G. D. (1998). Volunteer motivation, satisfaction, and management at an elite sporting competition. Journal of Sport Management, 12, 288-300.

Gammage, K. L., Hall, C. L., Prapavessis, H., Maddison, R., Hasse, A., \& Martin, K. A. (2004). Re-examination of the factor structure of the self-presentation in exercise questionnaire (SPEQ). Journal of Applied Sport Psychology, 16, 82-91.

Getz, D. (2007). Event studies. Theory, research and policy for planned events. Oxford: Butterworth-Heinemann. 
Gladden, J. M., McDonald, M. A., \& Barr, C. A. (2005). Event management. In L.P. Masteralexis, C.A. Barr, \& M.A. Hums (Eds.), Principles and practice of sport management ( $2^{\text {nd }}$ ed., pp. 272-294). Sudbury, MA: Jones and Bartlett.

Green, B. C. \& Chalip, L. (2004). Paths to volunteer commitment: Lessons from the Sydney Olympic Games. In R.A. Stebbins \& M. Graham (Eds.). Volunteering as leisure, leisure as volunteering: An international assessment (pp. 49-67). Cambridge, MA: CABI.

Haase, A. M., \& Prapavessis, H. (2004). Assessing the factor structure and composition of the positive and negative perfectionism scale in sport. Personality and Individual Differences, 36(7), 1725-1740.

Jackson, S., \& Schuler, R. (1985). A meta-analysis and conceptual critique of research on role ambiguity and role conflict in work settings. Organizational Behavior and Human Decision Processes, 36, 16-78.

Kahn, R. L., Wolfe D. M., Quinn, R. P., Snoek, J. D., \& Rosenthal, R. A. (1964). Organizational stress: Studies in role conflict and ambiguity. New York: John Wiley \& Sons.

Katz, D., Kahn, R., \& Adams, S. (1978). The study of organizations: Findings from field and laboratory. CA: Jossey-Bass.

Kline, R. B. (2005). Principles and practice of structural equation modeling $\left(2^{\text {nd }}\right.$ ed.). New York, NY: The Guilford Press.

Kodama, E., Doherty, A., \& Popovic, M. (2013). Front line insight: an autoethnography of the Vancouver 2010 volunteer experience. European Sport Management Quarterly, 13, 7693.

Lance, C. E., Butts, M. M., \& Michels, L. C. (2006). The sources of four commonly reported cutoff criteria: What did they really say? Organizational Research Methods, 9, 202-220. 
Love, A., Hardin, R.L., Koo, G.-Y., \& Morse, A. (2011). Effects of motives on satisfaction and behavioral intentions of volunteers at a PGA event. International Journal of Sport Management, 12, 86-101.

Merrell, J. (2000). Role ambiguity: Exploring the complexity of roles and boundaries when working with volunteers in well women clinics. Social Science and Medicine, 51, 93-102.

Mules, T. (2004). Evolution in event management: The Gold Coast's Wintersun Festival. Event Management, 9, 95-101.

Nichols, G., \& Ojala, E. (2009). Understanding the management of volunteers through psychological contract theory. Voluntas, 20, 369-387.

Nunnally, J. C., \& Bernstein, I. H. (1994). Psychometric theory (3 ${ }^{\text {rd }}$ ed.). NY: McGraw-Hill.

Ortqvist, D., \& Wincent, J. (2006). Prominent consequences of role stress: A meta-analytic review. International Journal of Stress Management, 13, 399-422.

Papadimitriou, D., \& Taylor, P. (2000). Organizational effectiveness of Hellenic national sports organizations: A multiple constituency approach. Sport Management Review, 3(1), 23-46.

Parent, M. M., Olver, D., \& Seguin, B. (2009). Understanding leadership in major sporting events: The case of the 2005 World Aquatics Championships. Sport Management Review, 12, 167-184.

Pearce, J. (1993). Volunteers: The organizational behaviour of unpaid workers. London: Routledge.

Pousette, A., Jacobsson, C., Thylefors, I., \& Hwang, C. P. (2003). The role of feedback in Swedish human service organizations. Community, Work, \& Family, 6, 245-268.

Ralston, R., Downward, P., \& Lumsdon, L. (2004). The expectations of volunteers prior to the XVII Commonwealth Games, 2002: A qualitative study. Event Management, 9, 13-6. 
Robinson, P. (2001). Task complexity, task difficulty, and task production: Exploring interactions in a componential framework. Applied Linguistics, 22, 27-57.

Sakires, J., Doherty, A., \& Misener, K. (2009). Role ambiguity in voluntary sport organizations. Journal of Sport Management, 23(5), 615-643.

Schulz, J., \& Auld, C. (2006). Perceptions of role ambiguity by chairpersons and executive directors in Queensland sporting organizations. Sport Management Review, 9, 183-201.

Schumacker, R., \& Lomax, R. (2010). A beginner's guide to structural equation modeling ( $3^{\text {rd }}$ ed.). New York: Routledge.

Shaw, S. (2009). "It was 'all smile for Dunedin!"”: Event volunteer experience at the 2006 New Zealand Masters Games. Sport Management Review, 12, 26-33.

Tabachnick, B. G., \& Fidell, L. S. (2013). Using multivariate statistics (6 ${ }^{\text {th }}$ ed.). Boston, MA: Allyn \& Bacon.

Tett, R. P., \& Meyer, J. P. (1993). Job satisfaction, organizational commitment, turnover intention and turnover: Path analyses based on meta-analytic findings. Personnel Psychology, 46(2), 259-293.

Thompson, D. P., McNamara, J. F., \& Hoyle, J. R. (1997). Job satisfaction in educational organizations: A synthesis of research findings. Educational Administration Quarterly, $33,7-37$.

Todman, J., \& Dugard, P. (2007). Approaching multivariate analysis. New York, NY: Psychology Press.

Toronto. (2013). 2012 Ontario Summer Games review and legacy update. Toronto: Government of Ontario. 
Tubre, T., \& Collins, J. (2000). Jackson and Schuler (1985) revisited: A meta-analysis of the relationship between role ambiguity, role conflict and job performance. Journal of Management, 26, 155-169.

Tucker, L. R., \& Lewis, C. (1973). A reliability coefficient for maximum likelihood factor analysis. Psychometrika, 38, 1-10.

Wolverton, M., Wolverton, M. L., and Gmelch, W. H. (1999). The impact of role conflict and ambiguity on academic deans. Journal of Higher Education, 70(1), 80-106.

Wright, B. E., \& Millesen, J. L. (2008). Nonprofit board ambiguity: Investigating its prevalence, antecedents and consequences. The American Review of Public Administration, 38(3), 322-338. 
Table 1

Pattern Matrix Representing Factor Loadings for Role Ambiguity

Factor

1

1 Performance Outcomes Ambiguity

How my work related to the overall objectives of the Games ${ }^{3}$ .949

What difference my performance made to my area ${ }^{1}$ .898

What difference my performance made to the Games ${ }^{1}$ .897

To whom I was expected to report ${ }^{3}$ .883

The impact of doing what was expected of me ${ }^{1} \quad .805$

$\begin{array}{ll}\text { If I was doing a good job }{ }^{1} & .774\end{array}$

What authority I had in my role ${ }^{3} \quad .761$

What would have happened had I not met the expectations of my $\quad .755$ position $^{1}$

How the work related to the overall objectives of my area $^{3}$

.682

What would have happened if I didn't perform my duties ${ }^{1} \quad .679$

The goals and objectives of my position ${ }^{3} \quad .626$

The extent of responsibilities of my role ${ }^{3} \quad .612$

What level of performance was expected of me during the Games ${ }^{1} \quad .582$

To whom I was most accountable ${ }^{3} \quad .568$

If I was meeting the expectations of my position ${ }^{1} \quad .508$

\section{Means-Ends/Scope Ambiguity}

What adjustments I needed to make to carry out my assignment ${ }^{2} \quad .903$

What I was expected to do in my role ${ }^{3} \quad .861$

Which of the expectations for my position were most important ${ }^{3} \quad .714$

The best way to accomplish my tasks ${ }^{2} \quad .645$

How to get my work done ${ }^{2} \quad .565$

$\begin{array}{lrr}\text { Eigenvalues } & 14.68 & 1.10\end{array}$

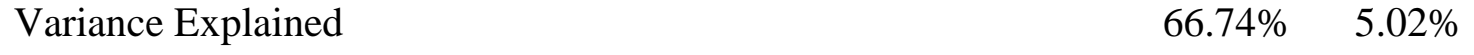

Note. ${ }^{1}$ Items from original Performance Outcomes scale, ${ }^{2}$ Items from original Means-Ends Knowledge scale, ${ }^{3}$ Items from original Scope of Responsibilities scale. 